\title{
FREGE, FATHER OF DISJUNCTIVISM
}

\begin{abstract}
The concept of the 'inner picture' is misleading, for this concept uses the 'outer picture' as a model; and yet the uses of the words for these concepts are no more like one another than those of 'numeral' and 'number'. (Wittgenstein, Philosophical Investigations, IIxi (p. 196))
\end{abstract}

Why disjunctivism, its seeming complexities and quirks? In the case of perception, Frege has a compelling answer. It gains him claim to fatherhood. (Cook Wilson is the natural parent in the case of knowledge. For singular thought, Russell will do as inspiration. The case of (reasons for) action remains to be explored.) My main aim here is to make Frege's case. A subsidiary aim is to begin to sketch some of its wider implications for the nature of our 'inner lives'.

Disjunctivism about perception and disjunctivism about knowledge oppose a common form of target. The target posits an ingredient in seeing, say, a lemon, or knowing there to be one, which could also be present in some range of cases where there was no such thing to see, or to know. For seeing, the ingredient is something of which the experience affords awareness. For knowing, it is an attitude one could hold anyway. The target (often) also holds that for one to see, or know, the thing in question is for this further ingredient to be present under suitable conditions, of whose obtaining one need not be aware.

But there is a disanalogy. Disjunctivism about perception concerns what experience provides to be responded to-if appearances, then things appearing (as experienced) thus and so, not one's holding of an attitude. Disjunctivism about knowledge concerns our responses - the idea of a response which may, or may not, be knowledge. For knowing $\mathrm{P}$, there does seem to be an attitude one could hold anyway even were there no such thing to know, namely, thinking that P. Current disjunctivistsas opposed to Cook Wilson-tend to grant that point. Their brief is then that there are no surrounding conditions which could make mere thinking so into knowledge. In the case of perception, it is nothing like apparent that there is the ingredient the target posits. Disjunctivism's brief, as presented here, will be that there is not. In which case, the further question whether seeing could be a hybrid of this ingredient and surrounding conditions lapses. Of course, something may look yellow, as encountered by an observer, where nothing is yellow. But such banal facts do not make for the ingredient the target wants there to be.

I will begin here by developing Frege's master point, with no further concern, for the moment, for what disjunctivism might be. I will then apply the point, first to a 
special form of disjunctivism's target, and then, generalizing the target, to a different case. This last case will be a form of intentionalism about perception. Some intentionalists believe that the supposedly recognized evils of sense datum theory are avoided simply by eschewing qualia, or special unworldly objects with visual, or other perceptual properties. Frege's lesson is that this simply is not so. To re-order one idea of Frege's: to judge is to expose oneself to error; there is something to judge to be one way or another only where something affords the opportunity so to expose oneself; such opportunities occur only in an environment. Intentionalism shares with sense datum theory a difficulty in respecting this idea.

1. Judgement: Let us think of the environment as home to all things to be met with. That subjectless passive is meant to signal two things. First, if something is to be met with, then there is no one one must be to meet with it. Second, if something is to be met with, then, for any meeting with it, there could have been another. I leave the idea of a meeting unexplicated except by example. Seeing, hearing, smelling, tasting, are each a form of awareness of things to be met with. One, say, smells the violets. The awareness thus afforded is a meeting with them. A proof that there is no largest prime is something one meets with, inter alia, in grasping it. The thought that tapirs are porcine may be met with in speculating about tapirs-in entertaining it. Perception being of what is to be met with, smelling the violets is a kind of meeting with them available to anyone suitably placed, and perceptually equipped. There is no one one must be for this.

Perception thus models occasion for a very special kind of attitude. I see a lemon only where there is one to be met with. I may respond to the experience with an attitude correct or not precisely according to whether there is a lemon to be met with. What correctness would be here points to a certain notion of correctness. The attitude thus correct or not exemplifies the special sort at issue here. Frege was concerned with a general case thus exemplified: attitudes whose correctness (of the indicated sort) is decided solely by things being as they are. He termed these 'judging'. So will I. The general case transcends attitudes towards the perceivable. Our problem: does it also transcend attitudes towards what is to be met with?

What is it for correctness to be decided exclusively, and precisely, by how things are? For one thing, whatever it is that decides this correctness should do such deciding as it does regardless of any thinkers' attitudes towards its so doing; so it should be there to do the deciding it does regardless of any thinkers' attitudes towards that. How are we to understand this? One thing we will need is: such an attitude may be correct, or incorrect; and if it is (in)correct on any taking of it, then it is correct on all. (This leaves 
out craving duck's tongues; also, quite likely, finding them delicious. It also makes the correctness at issue here contrast with being justified: in my Proustian bedroom, I may be unjustified in thinking it is snowing (the thought resting on nothing but intrinsic pessimism), while you, looking out the window, may be entirely justified in thinking so. But you are correct in the present sense iff I am.

One might want more. But to get this much we also need more. To make sense of an attitude being correct on any taking of it, we need to be able to separate what is to be correct or incorrect-a certain attitude available to take-from any taking of it. Where there is a judging, there must thus be that which is thus judged (a judgement). For us to be able to detach a particular attitude taken from a given case of someone standing towards things as he does, it must be determinate enough when, in someone's standing towards things as he does, it would be that attitude (inter alia) which he was taking. Which will be determinate enough if, but only if, it is sufficiently determinate how someone would stand towards the world (or things being as they are) in taking it.

One might plausibly think it also a requirement on detaching an attitude from some holding of attitude that the attitude detached be to be met with (in thought) - in grasping, or entertaining, it. Which means: there is no one one need be to take the attitude; and that for any taking of it there might have been another. Here, though, this calls for argument. Frege's concern in what follows is with whether, in someone's standing as he does towards things being as they are, there are detachable attitudes for him to take-that things are thus and so-which are available only for him to take, or, more generally, meet with. These will be attitudes towards what there is only for him to meet with-if not necessarily such-and-such items, in any case such-and-such ways for things to be. For there to be such attitudes is for the extent of how things are to transcend that of how things to be met with are. What Frege aims to show is that it does not.

Perhaps there is $a$ way of counting thoughts on which the thought $I$ think and the one you do, where we both think that I am cold are different ones. It all hangs on special modes of presentation of oneself. But then there is another. For in such a case each of us is right or wrong according to something in particular as to how things are: whether I am cold. One of us will be wrong as to that just where the other is. Which identifies an attitude we share, specifically, a judgement, we both judge. That there are also ways of distinguishing our attitudes is, for the present, beside the point.

In ordinary speech, the verb 'judge' has connotations of confronting something and sizing it up. I may, inspecting him, judge the man looking at me in the bar to be dangerous. But if I merely think, in my cork-lined room that it is snowing (manifesting 
my pessimism), that is not judging. So we ordinarily speak. But not here. To be a judgement is, here, and for Frege, just to be truth-evaluable. To judge is to hold a truthevaluable attitude.

To judge a pig to be wallowing is to be exposed to being right or wrong as to what is to be met with. What might it be to expose oneself to error, as one ipso facto does in judging, as to what is not to be met with?

2. Inner Confrontations: I now start an extended argument. Frege presents it in terms of an analogy. This section concerns the first term of that comparison. It does not draw the conclusion of the argument. For that the whole analogy is needed. So, in particular, it does not decide whether the realm of things for me to judge extends beyond that of judgements as to what is to be met with. It is but a first step towards such decision.

If there is something it is for a rubber ball, or towel, or sunset, to be red, it does not follow that there is something it is for the $\mathrm{E}$ flat above middle $\mathrm{C}$, or the rate of recidivism in Ohio, to be red. Those ideas may yet lack sense. There is, Frege tells us, another sort of case where new sense would be called for. He says,

The word 'red', if it does not indicate a property of things, but is meant to indicate marks of sense-impressions which are part of my consciousness, is applicable only in the domain of my consciousness. (1918, p. 67)

If I used 'red' to speak of things there for only me to meet with, I would not thus be speaking of a way for environmental things to be. So if I do use 'red' to speak of a way for environmental things to be, I cannot be speaking of a way for non-environmental things to be. 'Red' has a sense in which it speaks of environmental things-balls, towels and such. For it to speak of non-environmental matters it would need new sense. For, in its environmental sense it does not speak of a way there is for a non-environmental thing to be. If I encounter, say, looks, or patches, or visual sensations, to be met with only by me, then these can be red only on a new understanding of what something being red would be. So Frege tells us.

Why should this be? The answer must turn on the absence, in the nonenvironmental case, of certain materials present in the environmental one; materials which, when present, constitute, in whole or part, what it is for something to be red- 
what it is we say of something in so saying. Conspicuously, there are those two features the notion to be met with brings on board: there is no one one must be to encounter the thing which is red, or its being red; for any encounter with this, there might have been another. I will call these features recurrability. Recurring need not take time. I may later encounter what I now do. But someone else might encounter what I now do. To be reencountered is just to be encountered at least twice.

The notion recognize fits what can recur. One may register new encounters with the already met. One may also register what one encounters as instancing a certain way for things to be. Both these notions are of cognitive achievement: one goes right, where one might have gone wrong. One will go wrong on the second notion of success where one would not meet the supposed instancing in $a$ meeting with what was meant to do it. One may similarly go wrong as to what would count as something being thus and so, where such is demonstrated by other occasions of having being that in mind.

Recurrability allows making particular sense of 'would'. That peccary has a porcine look. Which means: there is a way it would look. When? On an encounter with it (barring reasons for it then not to). For it to have the look is for that to be met with by anyone suitably placed and perceptually equipped. A grasp of 'suitably' will be a grasp of when there would be such an encounter. Peccaries are dangerous in rut. This one would have been if in rut. Peccaries, and something being in rut, are both recurrent parts of the environment. A grasp of which parts is a grasp of when this peccary would have been in rut.

A ball's being red, as we conceive such things. is something with an etiology and with effects. (Being red has effects, which is why stop signs are.) If a ball is red, its so being so would be encountered on any meeting with it, barring happenings to change its colour. There are facts as to what would, or might, and what might not, do this. (Depending on the etiology of its being red, the sun might, or might not, fade the red out.) If you encountered a red thing in blue light it might look purple. If you encountered it in the dark, you could not detect its redness by looking. Each of these banal remarks make sense only given that a suitable 'would' also does. If the ball is red, then there is a way it would look in blue light. Recurrability gives us such a 'would'. Such facts as to what would be are part of what it is for a ball to be red. Recurrability is thus essential to the environmental, sense of 'red'.

Something is red just when its so being is to be met with. So, whatever it would be to meet with something being red, if it is red, then there is that to meet with on an indefinite range of occasions. If, say, being red is the sort of thing one can normally tell by looking (as one might expect if to be red is to have a certain look), then if the ball is 
red, that is something one could tell by looking on indefinitely many (actual or possible) occasions.

A ball's being red matters in a certain way to what there is to encounter in the environment. Nature has a large voice in just how. Nature's being granted such a voice is part of what something environmental being red is. Nature could so function only where a suitable 'would' fits. If the shirt is red, it need not be so that there would still be that look to be encountered on meeting with it after it was washed. But if not, that is because of what, nature being what it is, washing it would do. The key point: for something environmental to be red is for nature thus to matter to what would be met with in meeting the item. That is part of what it is, here, for something to be red.

So what being red is to be understood to be, and nature, decide jointly, in understandable ways, what there would be to be met with if such-and-such were red. The role of what is to count as something being red stands out clearly where there are contrasting understandings. This setting sun in Hackney is red on one understanding of it being so, not on another. How do these understandings differ? On the one, the sun need not then look red observed from Bristol. On the other it had better. The understandings differ precisely in what would be met with if, on each, the setting Hackney sun were red.

One should not expect, in general, to be able to tease apart the work of nature from that of what one understands by being red. What mattters is that the whole joint enterprise gets off the ground in the environmental case only thanks to what recurrence puts in place. That such a joint enterprise is off the ground is part of what it is for something to be red in the usual environmental sense.

Something's being red matters in determinate ways. For the environmental, what this mattering is to is what is to be met with. In the non-environmental case there can be no such mattering. When such mattering is stripped away, what would it be for something to be red? What it would be for an environmental item to be red does not yet answer this question. That is why 'red' needs new sense to apply in the nonenvironmental case.

What might it be for things non-environmental to be red? One might envision the following route to an answer. Delete from our usual notion of being red all the ways in which something's being red (or not) is liable to be a matter of what is to be met with. Then look at what is left. What is left? One suggestion: for something to be red is for it to have a certain look; having that look is a matter of what is to be met with in the environmental case. But perhaps there is still something it would be for something nonenvironmental to have that look: it is to be, or look, just the same colour as 
environmental red things. The idea clearly will not do. For it helps itself to the notion of looking thus and so. We know what it is for something environmental to look a certain way: there is something one would meet on meeting with it. But that idea does not fit the non-environmental case. So how are we to understand looking here? This notion, too, needs new sense (or an explanation of why not). There is so far no progress.

To be the same colour might be to be indistinguishable in colour. But what indistinguishability of environmental items comes to does not show what indistinguishability of the colours of an environmental and a non-environmental item might be. I may aim to make a soap, visually indistinguishable from a certain lemon. I succeed or fail according to whether there is a visually detectable feature of the lemon not to be met with in the soap (or vice-versa). A detectable feature is one which could be met with, and registered, in an indefinitely extensive range of encounters. It is what a suitably equipped observer would detect. If there is such a feature, then the suitably equipped could distinguish the lemon and the soap in indefinitely many encounters with them. There are, anyway, such encounters to be had. None of these ideas makes sense in the non-environmental case. For we have not made sense of the idea of what would be so on a meeting with something not to be met with. So, equally, nor of someone being able to detect something on a meeting. Someone with an ability is someone who would get things right on suitable occasions for its exercise. We do not yet know what it would be to get things right as to how things stand with something not to be met with. Surely not the same thing that it would be to get things right as to what is to be met with.

It is thus not obvious what remains of the notion of being red when its anchoring in what is to be met with is stripped away, or how anything left could, all by itself, allow us to make sense of something non-environmental being red. If there is no core understanding that could do this on its own, there is, equally, no core understanding which, on its own, determines what the right new understanding of being red is to be.

Any way for things to be has an intrinsic generality. Not everything in things being as they are would be required for things, or something, to be (or not to be) that way. There is what matters to being the way in question, and what does not. There is, accordingly, the range of cases in which things being as they were would be things, being the way in question. The range is always extendible: for any given members, there could always be another. For something in my inner world to be red would be for my inner world to be a certain way. It would be for something to be met with only by me, perhaps, only on the occasion, to be a certain way. The remarks about any way for things to be apply. In my inner world's being as it is there would be what mattered to whether things, or something, was that way, and what did not so matter. There would, 
accordingly, be the range of cases in which my inner world's being as it was would be things, or something, in it being the way in question. What is 'would' to mean here? And what should mattering in a determinate way amount to? We have, so far, no answers to these questions. Perhaps they have answers. This is but the first stage of an extended argument.

If one judged things, or something, non-environmental, to be, or appear, 'red', what way one thus judged things to be would not be fixed by what it is for something to be red. That is Frege's point. So it remains to be said what one would thus judge. That such-and-such is red is something one might judge. It is to be met with in thinking, just as something's being red is to be met with in seeing. One meets with it in meeting with something to which the environment matters in a certain way. Someone's so judging is, again, something to be met with. It is to be met with in the environment's mattering as it does to the way he thus guides his dealings with it. In identifying something to be judged of a non-environment (correlatively, ways it may, or may not, thinkably be), we cannot appeal to such ways of mattering. For they are intrinsically environmental. Whether there are things to be judged of a non-environment at all, and by what such things might be identified, thus remain open questions.

3. Background: Pausing between the two legs of Frege's argument, let us ask how to make sense of the idea of there being such-and-such, in particular, there to be judgedof someone judging thus and so in his current holding of the attitude he does. When would such a thing be present in someone's holding the posture he does towards things? Its presence would be that of something available to judge, even if only for this person then-available whether it had been judged or not; thus, if judged, then separable from the circumstance of its having been; identifiable anyway without that circumstance to refer to. It would represent a particular way for a thinker to expose himself to error; to stake his cognitive success on how things are. That particular way for things to matter to success would be a particular way for things to be. When may we sensibly suppose someone's attitude towards things to contain as elements such discriminable attitudes?

A judgement would be available, even where not taken. An attitude an open sentence expresses-taking something to be red, say-is available to take on different occasions and towards different things, including ones towards which it is not. An attitude expressed in a closed sentence-say, that this scarf is red-might have been taken even had things—even that scarf-been different.

We may speak of an attitude as there to take on various occasions only with an 
adequate notion of same attitude in place. Where the attitude is judging, we need an adequate notion of same way to judge things to be. The notion same, on its own, does not supply what we need here. Nor does the notion judgement, added to it. The usual applies here. Whether my violet singlet is the same colour as my purple shorts is not settled by what the same is, nor by that plus what a colour is. There are various ways of thinking of colours; room for various notions of same colour. Similarly for attitudes. Whether Sid and Pia think the same thing as to the colour of my shorts depends on what that thing might be. Find a sense in which they do think the same, and you ipso facto find something to judge in judging shorts a certain colour; something Sid and Pia did each judge. Fixing what judging the same thing might be and fixing a way to judge things come as a package.

Here, now, is an analogy (not Frege's). For its first term, suppose it were said of a given proposition-say, that that pig is wallowing-that it articulates into certain elements: being about that pig (or a feature that makes it so); and being about something wallowing. What could it mean to call these elements? Wittgenstein, in January 1930 (see Waismann, 1979, p. 90), had this to say. An element of a proposition is simply an identifiable respect in which that proposition is the same as some range of other propositions (that pig is grunting, that pig is snuffling, etc.): they are all thus alike. So it makes sense to speak of an element of a proposition only insofar as that proposition is part of such a range. If there were no such contrasting propositions, and if one could still represent that pig as wallowing, that representation would be unstructured, without elements. Its 'logical form' would be pigwallow.

The analogy's second term starts from a thinker at a time. There is his posture towards things: all his sensitivities, affinities, aversions, propensities to disappointment, deception, gratification, triumph, and to set, change, or hold, course-his engaging with things as he does. For him to judge such-and-such is for this posture to articulate; to contain this judging as an element. Perhaps one discriminable feature of his posture is his judging that that pig is snuffling. Now the analogy. Just as it makes sense to speak of an element in a judgement only where it is present in an identifiable range of judgements, so it makes sense to speak of an element in a posture-here the postureholder's judging thus and so-only where there is a range of postures it is (or would be) part of; a certain range of otherwise-different postures all alike in being, inter alia, ones of judging this.

An attitude thus just is a common element in postures. There are those cases of someone standing towards things which are alike in that they are all cases of taking this pig to wallow. That is one identifiable way for postures to be alike. A posture may recognizably contain this element. To judge that pig to wallow is to be exposed to a 
certain form of error as to what is to be met with. One might, say, misjudge the viscosity of the ground beneath the pig. One can (sometimes) see people to be wrong about such things. Their being so is to be met with. Such identifable samenesses in exposure to disappointment or surprise can unite a range of postures. They may thus identify something one might judge. Conversely, where there is something someone might judge, there are such samenesses in postures. This much must be so even if those samenesses are not in ways of standing towards what is to be met with; even if a posture could not recognizably contain them. The general point applies even for postures towards a non-environment. The question is what, there, a sameness between different postures might be.

Someone's engagement with the environment can itself be part of the environment. His liability to (in)corrrectness in his cognitive ventures can be to be met with-as is Pia's and Sid's discomfiture as, arriving for talk on tropes, they find the doors locked. (The talk must have been on Thursday.) Their discomfiture is to be met with: there is no one one must be to meet it. So can its cause: the locked doors, as is its being cause. Pia and Sid are guiding their environmental dealings as it would take open doors, or, better, a talk on tropes, to put right. Such things show themselves, as does a ball's being red, in what is to be met with in experience of the environment. One could, here, share something in common with Pia and Sid; be guiding one's one transactions in ways it would take the same to put right. Such an understanding of the same, in terms of what would be to be met with, is itself to be met with-shared-in thought.

Where it is the environmental towards which Pia guides her dealings, rightly or wrongly, we gain right to a now-familiar 'would'. Here guidance is as to what is to be met with, and is on or off target accordingly. The would we need-when things would be as Pia and Sid suppose-is already in that 'is to be met with', referring as it does to no particular meeting. They are right if a talk on tropes would be to be met with by anyone suitably placed at 3 . They would be right where this was to be met with. Someone else's posture would contain this element in theirs if he were liable to be right or wrong accordingly. For Pia and Sid both to think thus and so is for 'the same' in 'think the same thing' to have a particular sense. We have just fixed (roughly, perhaps) such a sense

What needs fixing is that range of circumstances in which someone would be holding such-and-such attitude which Pia does; that range of postures of which it would be part. We have just seen, in outline, how the environment can make such projects unproblematic. This fixing must be done somehow in the non-environmental case as well on pain of there being no thinking-so in a posture towards a non-environment. For any given way someone might judge his non-environment to be, sense must be made at 
least of when he would be judging that; of when that would be an element in his posture towards his non-environment. We must still think in terms of a range of postures towards a (perhaps his) non-environment, of which this judgement would be an element.

Engagement with a non-environment is itself part of a non-environment. A thought that a non-environment is thus and so cannot be identified by when it would misguide, or rightly guide, environmental dealings. For then it would be right or wrong according to how the environment was, thus a judgement as to how the environment was. Rather, it must be identified in terms of transactions with what (at most) only one thinker could be aware of, so transactions of which (at most) only one thinker could be aware. So that a thinker stood in the same way twice towards his non-environmentthat, say, he once, then, took, and now, again, takes, it to be thus and so, or that he would now take it to be thus and so if he were now thinking in such-and-such way could be something at most he could ever recognize. How what he thus thought might serve aims would be again for him alone to recognize. It would be unlike identifying an element in postures by its rightness or wrongness in guiding one to lecture rooms at certain times.

But recognizing is an ability. To recognize the same thing to have been present twice is not just to take it to have been. It is registering a circumstance which could still have obtained unregistered. The problem here is in what such a circumstance might consist.

What there is to recognize, in present matters, is when, on a certain understanding of the same, the same had occurred twice. In the environmental case a thinker might go wrong in taking this to have happened in either of two ways. He might be wrong as to what had occurred in the one case or the other. Or he might go wrong as to whether what did occurred counts as the same thing twice. In the second case he would mistake what was to count as the same-here, as thinking such-andsuch. What is to count, here, is graspable by indefinitely many. He may be shown wrong by what indefinitely many would thus see. In the non-environmental case, going wrong in this second way cannot be like that. Someone cannot, in that way, have the wrong understanding of the same as it occurs in some particular idea of his having the same posture twice towards his non-environment. For only he can have any such understanding: only he can get in mind those things that might, or might not, so count. Perhaps, then, there is no such second way for him to be wrong here: the right understanding of same attitude is just the one he does have; a matter of what he would, thus of what he does, reognize. But it cannot be like that. He was meant to grasp what his holding the same attitude twice would be. That he says such-and-such cannot constitute 
grasp of anything. Which prepares us for the second leg of Frege's argument.

The idea judge that $P$ has sense only where someone so judging is liable to recur. What it would be for so judging to recur (occur twice) in postures towards a nonenvironment cannot be what it would be for it to recur in the environmental case. Just as we saw with being red, the notion same attitude and with it the notion judge that $P$, require new sense here. I have not yet said that no such sense could be supplied. Whether it could is the topic to be considered next.

4. Truth ${ }^{*}$ : Frege's treatment of red is the first term of an analogy. Here is the second:

I said that the word 'red' would only be applicable in the domain of my consciousness if it did not cite a property of things, but only indicated certain features of my sense impressions. So, too, if the words 'true' and 'false', as I understand them, didn't concern something I am not the bearer of, but were fixed so as to characterize, somehow or other, contents of my consciousness, they would be applicable only in the domain of my consciousness. Thus would truth be limited to the contents of my consciousness, and it would remain doubtful whether anything similar occurred in the consciousness of another. (1918 pp. 68-69)

Frege tells us here that if a thought needed a bearer, then the sense (if any) in which 'true' and 'false' applied to it would not be one on which they apply to the thoughts it is open to one to think about environmental matters. By argument parallel to that in the case of 'red', this means that for 'true' to apply to a thought that needed a bearer, 'true' would need new sense-a sense not fixed by its sense on its environmental applications.

For a thought to need a bearer would be for it not to be met with in thought, but only to be met with (on suitable occasions) in so-and-so's thought. Meeting a thought in thought would be thinking it, or entertaining it (considering whether things are that way), or thinking of things being as they are according to that thought, in thinking something more complex, or just grasping it-seeing what it would be for things to be as that thought has them. To think the thought would be to expose oneself to error in a certain way. For a thought not to be met with, only one thinker could expose himself in that way. 'To be met with' here has its (presently) usual subjectless sense. A thought to be met with is one one might meet with in thinking in the right way. 
Truth began life as part of a package. It was a particular kind of correctness (contrasting, e.g., with being justified), where explaining what kind of correctness that is and explaining what special sort of attitude judgement is are one and the same enterprise. To be a judgement just is to be subject to that sort of correctness. Frege tells us here that to speak of thoughts which require bearers is to sunder this package. Such thoughts would be 'true' only in a new sense of the word. Which is to say that the sort of correctness to which they are liable is not the sort which makes for judgement. What it is is not fixed by what truth is. For something to be red is for its being as it is to matter in a certain way to what is to be met with. Correspondingly, for there to be a question as to whether it is red-for it to be what is liable to be red-is for what is to be met with to matter in a certain way to that question's answer. Similarly, for a given judgement to be true is for its standing as it does towards things to matter in a certain way to what is to be met with. And for it to be liable to truth-for the question of its truth to arise-is for what is to be met with to matter in a certain way to that question's answer. A thought needing a bearer is not liable to be true. No such question arises. Things being as they are cannot matter to its answer. If it is liable to any sort of correctness, things being as they are must matter in a determinate way to whether it is correct in that sense. But such liability would not make for judgement. Whereas what we needed to find room for was precisely judgements about a non-environment. One might envision a new package: truth $^{*}$ and judgement ${ }^{*}$, each explained in terms of the other. The old package does not tell us how such explanation might go. Nor is it clear what interest such a new package might have. So we may see Frege as a bit laconic here, as if, seeing the Ching vase smash on the slate floor, one opines that it will never be quite the same again.

But we need worry only if a thought about a non-environment would be a thought that needs a bearer. The case for that starts here: to be a thought is to have a certain generality. It is not just that things being as they are is, or is not, things being as that thought has them. If things were, or had been thus, or, again, so, that would be things being the way they are thus thought to be. So, as already noted, for any thought there is an indefinitely extensive range of cases in which things being as they were would be things being the way they are thus thought to be. For a thought about the environment, a case within the range is one of to be met with being thus. For a thought about my non-environment, a case within the range would be, in at least indefinitely many instances, something only I could meet with. Only I could be acquainted with it. So only I could think of it that this is a case of things being the way in question. To grasp what it is that is so according to the thought would be, inter alia, to grasp, or be able to grasp, of what would be things being that way (and of what would not) that this is being the way in question, this not. Such singular thoughts (turning precisely on the 
status of things being thus) are ones available only to me. Only I could be acquainted with their being thus. So only I could grasp what the generality of this thought was. So only I could grasp it. Which is just to say that such a thought would require me as its bearer. It could not be to be met with.

The initial hope was that what I encounter in my inner world may be things being some very same ways that what is to be encountered in the environment may be. I could thus judge things to be, or not, those ways. Such thoughts, the idea was, would not need a bearer. Though you can never see that which I judge to be this or that way, you could at least grasp what I judge of it-that, say, it is red. The first leg of Frege's argument dashed such hopes. To grasp what it is I was thinking in thinking something environmental 'red', you would have to grasp that new sense which I attached to 'red'. But grasping the range of cases in which things would be red in this new sense is beyond your reach. So these hopes are dashed.

If there were a way which both environmental things and objects of my nonenvironmental encounters might be, there would be a range of cases in which things being as they are would be their being that way, where you could think these to be such cases-the environmental ones-and a range such cases which you could not think to be such cases-the ones where objects of my non-environmental encounters were the relevant way. The range of which you could think would not determine what the range of which you cannot think should be. What you can grasp as to what the generality of such a thought would be leaves undetermined what its generality in fact would be. So you cannot grasp the thought. This is a way of appreciating just how right Frege was about 'red'. It now means: thoughts about a non-environment do need a bearer.

Frege tells us: what it would be for a thought about what is to be met with to be true does not fix what it would be for a thought that needs a bearer to be true. A thought about what is not to be met with (in our present sense) would be one case of a thought which needs a bearer. So a thought about a thought about what is not to be met with, since a thought about what is not to be met with (in thought) would need a bearer. So a thought about such a thought that it was correct, in some form in which it might be — call that being true* - would need a bearer. It would not be a thought that we could think or grasp. A thought about a non-environment would still need to be a common element in some range of postures towards that non-environment. But as to which range of postures this was, only the bearer of the thought could so much as have, or grasp, a view. A thought about a non-environment could not be true. Which is to say that true, like red, is an environmental notion. I will return to defending this idea. But suppose, for a moment, it is right. 
If truth is an environmental notion, then one may judge one's inner world to be thus and so only on a new notion of judging, call it judging*. What one judges-that such-and-such-is a judgement only on a new notion of judgement, judgement ${ }^{\star}$. A judgement was to be what is liable to a certain kind of correctness: truth. But now correctness can be truth only on a new notion of it, truth*. It would be decided by how things are only on a new understanding of being decided by how things are. Can we introduce such notions?

To make sense of any notion is to fix (adequately) what it would be for it to be true of something, or when it would be. For it to make sense is for there to be such a thing as when it would be true. So one thing that needs fixing here is what it would be for true* to be true of something-specifically, of something not to be met with in thought, neither thinkable, nor graspable, except, at most, by one thinker. Which, as we have seen, is what a judgement about a thinker's non-environment would be. 'True', if an environmental notion, would not apply to what 'true" thus did. So nor would it apply to such things being true*, nor to a thought (if there were one) that something was true*, neither of which would be something to be met with. There is nothing it could be for it to be true that such a thing was true*. There is no such thing as "when true* would be true of something'. So there can be no fixing this. There is, accordingly, no such thing as making sense of any of the family of required new notions just listed above. There can be no such thing as truth*. Truth admits no substitutes. There is, accordingly, nothing to be judged in a would-be thought that needed a bearer. There are no such thoughts. The idea of merely 'judging*' them cannot help here. There are, thus, no thinkable way for a non-environment to be.

Must the notion true figure in making sense of any notion? Suppose we want to make sense of something being red*. Would it not do just to say what it would be for something to be red ${ }^{*}$, or when something would be that? Truth need not be mentioned. But truth need not be mentioned to figure in thought. It is what thought aims at. There is such a thing as something's being red* just where there is such a thing as the range of cases in which something's being as it was would be its being red*. That is just the range of cases in which something would be as judged in judging it red*; thus, in which the correctness of such a judgement would be decided solely by things being as they are. Correctness here, to belabour the familiar, is truth. So where we can make the right sense of being red —of something's being as it was being what was needed for its being red $^{*}$-we can make equal sense of the idea of its being true that the thing is red*; and vice-versa. For 'red" we may substitute any way for things to be, notably, the supposed true*. We cannot make sense of its being true that something is true*. So we cannot make sense of something being true*, full stop. 
What it would be for something to be red is fixed just so far as it is fixed in what range of cases something's being as it is would be its being red. An understanding of what it would be for something to be red is formed in part by what one is prepared to recognize as to what, specifically, would, and what would not, count as something's being red; so (in part) by thoughts, of particular cases of things being as they are, that this would so count (or not)-thoughts tied to a particular circumstance as a singular thought is tied to an object. An understanding available to some one stretches only so far as there could be something he was prepared to recognize in such matters, so only so far as the singular thoughts, of the above sort, he could intelligibly be credited with thinking. So the understandings available to us jointly of what it would be for something to be red-those understandings to be met with-extend only so far as what it would be for things to be met with to be red. That is why 'red's usual sense does not make it applicable in a non-environment. What belongs to that range of cases of something's being red leaves it open what would belong to some other range, notably, one including cases of a non-environment being as it is, or its inhabitants being as they are. For all the sharable understanding fixes, any such range would do as well as any other. Red is not something something non-environmental might be.

Mutatis mutandis for being true. Our understanding of being true extends no farther than cases where what is true, and its being so, are to be met with-cases in which one could think, of what is true, that that is true. Such a range stops short of thoughts not to be met with. Nor does it fix what range of such thoughts would be the true ones. By the above, then, there is nothing it would be for a thought not to be met with to be true. Nor does truth admit of substitutes. There is no way to introduce one. Things count as a certain way just where it counts as true that they are that way. So nor is there such a thing as when a non-environment (or what belongs to it) would be suchand-such way. My inner world being what it is (if that is anything) cannot consist in its being such-and-such ways. The last leg of Frege's argument brings us to this point.

I have so far supposed that truth is an environmental notion. It applies only to thoughts which do not need a bearer: if that thought is that such-and-such, one need not be so-and-so to think that so.) This combines with the idea that a thought about something non-environmental would need a bearer to deliver this result: the idea of a judgement about the non-environmental has no sense. But one might resist the idea that truth is an environmental notion. Frege tells us:

The meaning (Bedeutung) of the word 'true' is unfolded in the laws of being true. (1918., p. 59) 
Being true is what those laws (the laws of standard logic) thus unfold. Such laws are purely formal. If they exhaust truth's content, then one might suppose that so is truth. A purely formal notion, on might think, cannot require only environmental applications.

But this idea is true neither to Frege nor to truth. Frege's laws of being true chart (mirror) connections between thoughts; specifically, inferential, notably truth-preserving ones. But the idea of truth begins with a thought about the relation of an attitude to its object-of a representation to that which it represents as some way or another. Such relations, though part of truth, are not the inferential ones those laws mirror; not relations between judgements (or their contents). Judgement was to be that attitude liable to a certain kind of correctness, a kind settled solely, by things being as they are. Such correctness of a judgement that the wind is howling is settled solely by the presence, or absence, of howling wind-by meteorological conditions. The way in which reigning conditions settle it is one way in which a question of truth may be settled. That its truth is so settled by things being as they are is thus a very small partial unfolding of the notion true: here is one way to be liable to truth and falsity.

To think that $P$ is to be exposed, in a particular way, to error or vindication. In the environmental case error has a certain sense. An attitude towards the encounterable is in error, if at all, as to how things re-encounterably are. For someone so in error, that which he is wrong (or right) about is to be encountered in an indefinitely extensive range of meetings. Its being an error matters systematically, in the usual ways, to what one would encounter. Here we are entitled to a 'would' which makes sense of these ideas-as, too, the idea, when someone would be making this error. If circumstances were thus, one would still be making it; if they were so, then not. So this 'would' which comes along with reencounterability, allows identifying a specific generality for a representation of something as so to have: that particular generality which goes with the issue whether P. Only with such a generality in place can there be talk of thinking something so.

A stance towards what was not to be met with, if it were liable to a correctness conferred or withheld by how things not to be met with are, would not be an attitude to be met with in thought. Still, were there such a stance, there would be that range of cases in which to hold it would be to be in error, and that in which holding it would be being right. Here, though, the usual notions of error and vindication do not fit. Nor can we understand the 'would' in 'would be in error (right)' as we do where error (correctness) is to be met with. To make sense of the idea of judgement here we would need new sense for 'error' and for 'would'. The point of the above argument is that there can be no such thing as the senses we thus need. 
Eligibility for truth goes with eligibility for error. My grasp the generality of a particular thought—of what range of cases would be ones of its error, what cases would be its correctness-extends no farther than my ability to think, of a case in the range, that it is such a case. So our grasp of a particular thought's generality, so of its being true, extends no farther than re-encounterable postures towards the re-encounterable. The range of such cases of something being an error, and of something being true, leaves it open what range of cases would be ones of stances towards a non-environment being in error, or true. What error comes to where it is re-encounterable does not tell us what it would come to where it is not. So, too, for truth. Thus it is that truth is an environmental notion.

Frege's target here is the idea of ways a non-environment may be judged to be; an idea of judgements true or not according to how it is. That idea aims to hold two things together. First, what one encounters in a non-environment is to be part of how things are. So to judge of it is to be correct or not according to how things (there) are. Second, how things there are is not integrated with how things otherwise are. It is independent of what one would meet with in meeting what is to be met with. The project is, perhaps, not absurd on its face. But it is unsurprising that it should founder.

'How things to be met with are' is pleonastic. 'How things are' would speak of just the same. For something to be true is for it to be vindicated by things being as they are. Nothing else could decide truth. Pleonastically put, for something to be true is for it to be vindicated by things to be met with being as they are. This is what Frege proved.

5. A Simple Disjunctivism: Seeing is a kind of awareness of (some of) one's surroundings. It furnishes occasion for responding-in attitude, affect, or action-to what one is thus aware of, or to its experiencing. Here is an intuition. I see the lemon on the sideboard; there is a way things then look. Things could be for me, visually, just as they thus are even were there no such lemon to be seen. This would not (just) consist in my being delusional-convinced of many things which simply were not so. Rather, for things to be visually for me just as they thus were would be for there to be something in the experience for me to be visually sensitive to, which I was thus sensitive to. For there to be just that for me to be aware of would be for things to be visually for me just as they were where I saw the lemon. This supposed ingredient in an experience of seeing a lemon and all those in which things would be just the same for me I will call a common factor, or CF.

So where I see the lemon, there is also a certain CF for me to be aware of. Another intuition: that CF could be there no matter how my surroundings were, and no matter 
what other experiences were to be had, 'could' here meaning there is such a thing as that. Things could be that way without me being simply delusional. Being delusional is a matter of one's (would-be) responses to what is going on. A CF is something there is for one to respond to.

Where the $\mathrm{CF}$ is present, either I see the lemon or I am having a perfect (visual) ringer for that experience. There are, the idea is, no visual clues, registering which would be a way of telling that I am was not seeing the lemon. There is no other way things ought then to look. The thought, again, is that things could be thus no matter how things not then experienced were arranged.

Disjunctivism is a negative thesis. It rejects the idea of a CF, present where I see the lemon. Perhaps where I see the lemon there is a way things visually are for me. But the idea of a CF is not a way of making sense of that. Nor, in general, for seeing, hearing, smelling, etc. A simple disjunctivism chooses a simple target. In this version the CF in seeing the lemon is itself an object of visual awareness, e.g., things ((as) experienced) looking such-and-such way.

The crucial idea here is: things look a certain way. It need not be that some thing does. On some versions of the simple version there will be such a thing-a sense datum. But there need not be for something to qualify as the present target. The lemon is, and, moreover looks, yellow and pebble grained. Those are both features it has. If I see it, I take in its having them. So one might posit an ersastz-lemon, eligible to be present, and an object of visual awareness, no matter how the environment is in fact arranged, and postulate that it, too, looks yellow and pebble-grained. But also, when the lemon is present things look a certain way. Here 'things' picks out the scene in view: the lemon, the sideboard, the tiled floor. If the CF is things looking thus and so, 'things' cannot be that. For there need be no scene before me. Still, it might be held, things appear (look) as would a scene which looked a certain way. An experience may be like that; which, the idea is, imposes another good reading on 'things'.

On this story, when the CF is present, things appear as if yellow and ovoid, or as if something yellow and ovoid were there. Now Frege's point has application. We must be careful to apply the whole, and not just the first half, of his argument. Here is a particular way things, on the present use of 'things', appear. 'Yellow and ovoid' we are told. I may judge (take) them so to appear. I may thus register things appearing the way they in fact do. (Or, if mistakes are in the cards here, get things all wrong.) But things appearing as they thus do is not something to be met with. For their so appearing is, by hypothesis, independent of what would be met with in any other meeting with anything. (The motivation is: no matter how all that may be, things could still be the 
same for me in the particular experience I am then having. I could still have that much cause for taking myself to see a lemon.) So, by the first leg of Frege's argument, 'yellow' and 'ovoid', in their above deployment, cannot have their usual sense (by which I mean all and only the sense they have on their environmental applications). (Being ovoid, for example, cannot here be the sort of thing one might establish, or disprove, by measurement. It is not what a 'primary quality' was meant to be.) If they are to apply at all here, they call for new sense. Their usual (environmental) sense does not decide what this new sense is to be. 'Yellow and ovoid'? When would things, on the current use of things, appear (as if) that way? When would one be taking things, on this use, to be just that way? These questions as yet have no answer. None is to be derived from the environmental uses of 'yellow' and 'ovoid'.

Perhaps, then, 'yellow' and 'ovoid' have some other sense, which they bear in such applications. The modifier 'phenomenal' might be (perhaps has been) meant to signal it. But just what are these senses? For there to be an answer to this question (forget whether anyone could ever give it), there would have to be an answer to the question when it was true of things (on the present use of 'things') that they were phenomenally yellow (or ovoid). There could be no answer to that precise question, because 'true' could not apply to judgements that things were phenomenally yellow. That is the first stage in the second leg of Frege's argument. So one might try to tell the needed story here by appeal to some substitute notion, 'true ${ }^{\star \prime}$. But the second leg of Frege's argument shows that there can be no such substitute notion. So there can be no such thing as 'things being phenomenally yellow'. And so on in general. This completes the application of Frege's argument to this simple case of disjunvtivism's target.

6. A Wider Target: 'Vorstellung' is a usual translation of the word 'idea' as it occurs in $18^{\text {th }}$ century British philosophy. Related uses may carry visual, or other perceptual, connotations. But such connotations are not essential to Frege's use of the term. When Frege asks whether a thought can be a Vorstellung, he does not suppose that his question is already answered by what he has previously stressed, that

A thought is something non-sensory, and all perceptually observable things are excluded from the domain in which truth can come into question at all. $(1918$, p. 61)

Rather, what makes something an idea, or Vorstellung, in Frege's terms, is the way in 
which it attaches to a particular bearer; in present terms, its belonging to an inner, or a non-environment. This suggests that we may now widen the target susceptible to Frege's core point.

The target: In the version of disjunctivism's target on the table so far, the common factor-present where I see the lemon, also eligible to be present where I do not-is something of which, whenever present in my experience, I am, or can be, visually aware. There is something it is visually like. Common factors in the wider target need not be objects of perceptual awareness, nor need there be anything they are perceptually (e.g, visually) like. The target's more general form can be this. When I see the lemon I am in a certain conscious state which I could be in where there is no lemon to see; more generally no matter how things yet unexperienced stood. I would be in this state when seeing the lemon and whenever having a perfect illusion thereof. Optionally, if I am in it then either I see the lemon, or I am having a perfect illusion thereof (it is for me just as though I were seeing the lemon).

It remains to say what the common factor is wherever one is in such a statewhat is present whether or not I see the lemon. We might try this. For me (or one) to be in that state is for my (or one's) experience to have a certain intentional content-that is, a representational content: it's being represented as so that things are a certain way. Where I do see the lemon (and surrounding scene), things are as thus represented. On the view in question, that is meant to fix what the relevant representational content is. For things to be like that is for them to be the relevant way. But my experience might have that content where I did not see the lemon, and, in fact, no matter what there was to see, or to experience, in my environment. (Byrne and Logue (forthcoming, section 5) present and defend this version of disjunctivism's target.)

Experience furnishes things for us to respond to. (At least it does when it involves witnessing, and is not mere undergoing (cf. Hinton 1973. especially pp. 5-21)). It is occasion to respond to them. One may so respond in responding to one's experiencing (e.g., seeing) them. The intentionalism just described is present disjunctivism's target on two conditions. First, the representing just posited must lie on the side of what there is to respond to, and not just on the side of a response to it. It will do for this, for my purpose, if the representation in question does not consist in the subject representing things to himself as so-taking, thinking, supposing, noticing them to be so, etc.

Second, in having the experience the subject must be afforded awareness of things being so represented, in the sense that this is something he is thereby prepared, or equipped, to recognize about the experience: if things prove thus-e.g., there proves 
to be no lemon-then the experience was not right; things are not as they were according to it; if things prove so, then they are as the experience had them. For there to be representing here is for there to be a way things would be if the experience were right; the experiencer can recognize when things are that way. Preparedness to recognize such things where they are so is all I want of the idea that the subject is aware of how, in the experience, things were represented to be.

The relevant representing thus cannot be entirely inaccessible to the experiencer, merely a feature of some sub-doxastic state, though this says little about what access to it might be like. Such access might just be things appearing to be, or as though, a certain way. Anyway, the idea here is that experience can be true, or untrue to how things are; and that the subject can grasp what being true or untrue would come to in the case at hand; when the experience would be true, when untrue. I see no reason to think that things are represented as so in subdoxastic states. But that is another story.

How things are represented to be, while the subject is in the postulated conscious state, is, in this sense, recognizable by him. So if things were represented differently, or not at all, that, too, would be recognizable. For the subject to be in that state is for things to be represented to be a certain way. So if he were not in that state, but rather some other, this, too, would be recognizable. For then things would not have been represented as they in fact were.

John McDowell's version of representationalism (for example) meets both conditions. He tells us,

Minimally, it must be possible to decide whether or not to judge that things are as one's experience represents them to be. How one's experience represents things to be is not under one's control, but it is up to one whether one accepts the appearance or rejects it. (McDowell 1994, p. 11)

A subject, confronted with a pig in plain view before him, may represent it as so to himself that there is a pig before him-that is, take there to be one. It is not then up to him whether to accept that things are as thus represented. He has accepted it: that is what taking-to-be is. Nor can one decide to accept or reject what one cannot be aware of. (Moreover, if there is any sensible question as to whether to accept or reject that things are as represented, then there is such a thing as their not being, though, also, they might be that way. So the representing is a common factor in cases of perception and 
some range of others, though McDowell does not here say that this common factor could be present no matter how the environment were arranged.) Thus, McDowell locates the representing he posits so as to meet both of my conditions.

These conditions are motivated by a role which, as I understand things, representational content was meant to play. Suppose that, looking at a wax ringerlemon I take myself to see a lemon. That is understandable, reasonable: so one might well do, experiencing what I did. Something about the experience speaks in favour of it. Nor is it merely, e.g., that I cannot tell a lemon from a lime. Sight furnished no clues that things were otherwise. Representational content is one way to explain what here is understandable: one might well take oneself to see a lemon because things were so represented. There is that much reason for me so to take things. Such content is reason for me so to suppose only if recognizably present in the experience in the minimal sense set out; not, e.g, as an undetectabe part of a sub-doxastic state (which could at most cause my responses). More generally, such explanation works only be appeal to something to respond to, not to a response, especially not one thus to be explained.

Does such representing admit of ringers? For a conscious state in which things are represented as being $\mathrm{F}$, could there be a different one in which things are not represented as that way (but, perhaps, as some other way), but where, for one in this different state, this would be unrecognizable? The ringer state would be one in which things were represented as being, not F, but, say, G. But the consciousness enjoyed by one in the state would provide no means for him to tell that. I think I see a lemon, say. But it is wax. So I am wrong on that count. I think that if there is no lemon, then my experience presented things to me as they are not. But wrong again, though undetectably. What was in fact represented as so is that there was either a lemon or a replica before me. Does this idea make sense?

One well might take a wax ringer for a lemon. They look just the same. That makes this error understandable. Intentionalism is meant to relieve us of need for such explanation. It provides a substitute: representational content. Such content is apt to be available where ringers are not, e.g., in an hallucination. So if it is represented as so that there is a lemon, that makes it understandable that one should think so, just as a ringer's looking like a lemon would.

For it to be represented that there is a lemon is not for me to think there is. I can distrust representations. But if there is a ringer for things being so represented, then it is similarly understandable that I should think things were so represented-that I should blame my experience for being untrue to how things are. Something must explain this being understandable. If intentionalism is to the rescue here, then that thing will be its 
being represented as so in this experience that things were so represented.

Such would be detectable (recognizable) in the current minimal sense. Since nothing recognizable in this ringer state marks it as a ringer (by definition), this further detectable feature would be shared by the ringer state, by the state in which it was represented as so that there was a lemon, and by some range of others in which, also, it was not represented as so that there was a lemon-but was represented as so that this was represented as so. There would be a conscious state I am in where I see the lemon, also where it is merely represented as so that I do, and also in a range of cases in which neither of these things is so. Such a state would have two explanatory burdens. First, where I neither see the lemon nor is this represented as so, it explains why I might think it was represented as so that there was a lemon. Second, it thereby explains why I might think I saw a lemon. That things were so represented cannot do the job in this case. For things were not so represented.

The idea of ringer-representing now collides with what called for representing in the first place. The idea was: where I see a lemon, I also experience a common factor, present there, and also in all experiences which provide no ways of telling, perceptually, that they are not ones of seeing the lemon-all ringers for doing so. In any such range of cases something speaks in favour of my taking myself to see a lemon; something makes it understandable for me to do so. That something is to be the common factor. With ringer-representing, the common factor is not its being represented that there is a lemon, but rather its being represented that things were so represented. So this last must do the explaining in all ringer cases. Nor could we rest there, or with any other determinate iteration of 'It was represented that' once ringer representing is in the cards. Whereas if it is disallowed, then the range of ringer cases extends no farther than those in which it was represented that there was a lemon. Such representing can then be what makes things understandable.

If a third state were called for, there is anyway a problem as to what it ought to be. For then there are two states (the initial one and a ringer for it) which would in no way differ in what was recognizable to me about my experience if I were in them. In one things are represented as a way they are not if there is no lemon. In the other they are represented as a way this still may be-e.g., if there is a wax replica. Which of these states should the third state represent me as in? And why? I do not think this question could have an answer. I also think it points to a problem with the very idea of representation in experience. But I drop the point and turn, instead, to Frege.

Frege's point: The representations posited above can just be of the environment as being thus and so. The features they ascribe to it are ones for environmental things to 
have-being red, say, in the usual sense of 'red'. Problems raised by non-environmental ways for things to be do not arise yet. But our suspicions should be aroused. We have a perfectly adequate understanding of what it is for something to be red. If we help ourselves to the idea that something non-environmental might be red on that understanding of so being, our straightforward version of disjunctivism's target becomes unproblematic. But it is problematic. We may not help ourselves to that idea. That is Frege's point. Similarly, we have a perfectly adequate understanding of what it is for it to have been represented as so that such-and-such where this is an environmental matter (as where it says so in the Times). If we help ourselves to the idea that in a non-environment it might have been represented as so that such-and-such, on that understanding of something being represented as so, then, again, all the rest is unproblematic. But may we help ourselves to this? Would not Frege's point apply?

For a lemon to be on the sideboard is for the environment to be a certain way. For it to have been represented as so that a lemon is on the sideboard is for the environment to be a certain way only if that representing (its occurring, or its production) is to be met with. An instance of the presently postulated representing is to be met with by me, say, by my being in a certain conscious state. It is to be met with then by me in what my being in the state makes recognizable to me about it-what I am thus positioned to tell, in the above minimal sense, as to when things would be as, in it, things were presented. That things were so represented can be available only to me, then. For, conversely, that representing could have occurred no matter what was to be met with; no matter how things were of which I was not conscious in (or while) being in that conscious state.

So the postulated representing of something as so is not something to be met with. Which places us in familiar territory. We know what it is for it to be represented as so that $\mathrm{P}$, e.g., in talk. Here things having so been represented-the talk's being so to be taken-is something to be met with. One may make mistakes about such things. One may misunderstand. There are familiar ways to learn of this. Facts about the circumstances of the talk, about the familiar usage of the words used, about the use made of them in this case, may all emerge in further encounters, e.g., with the words used, and with those presumed to be familiar with them. There are things with the recognizable shape of a demonstration that things were actually represented this way, rather than that-that, say, Sid was not really to be taken to have been speaking of dinner when he said, 'Pia had a little lamb.' None of this could be part of what it would be for things to have been represented as thus and so in one of the postulated conscious states. Which is to say that, in this case, the expression 'represent it as so that $\mathrm{P}^{\prime}$ requires new sense. The phenomenon it speaks of as instanced, e.g., in talk simply does not fix what phenomenon it would be speaking of in the case of these conscious states. That is 
for the new sense to do.

That in such a state it was represented as so that $\mathrm{P}$ is meant to be the content of a judgement. So there is meant to be something in things being as they are on which the truth of such a judgement might turn; something which, if present, would make the judgement true, and if absent would make it false. Something thus to judge about; something for its thus being represented as so to be. But the question now is on what the truth of such a judgement might turn. That is a question only new sense for the notion represent as so could answer. Which again places us on familiar ground.

If there is such a thing as representing it as so, in such a state, that $\mathrm{P}$, then there is a range of cases in which, in such a state, that is how things would be represented. But the particular cases in which things were so represented in my states of the postulated sort would be ones which only I could get in mind. Only I could be acquainted with the representing thus occurring; only I could have thoughts of it (in a given case) that it was thus and so. Only I could see what the relevant generality was to be here-that belonging to the notion represent as so that $P$, on its application to my (relevant) conscious states. So only I could grasp the thought, of some such state that I was in, that in it what was going on was its being represented as so that $P$. Again, the trouble is not with the notion that $P$, but rather with the notion of representing as so, applied in this domain. Thoughts to the effect that this is the way things are according to (the representing going on in) this state would be thoughts that needed a bearer. But that means, as we have seen, that it could be 'true' only in some new sense of true. And, as we have also seen, there can be no such new sense. Which answers the question what there could be for a judgement that in such a state it was represented as so that $P$ to answer to: nothing. In what way could it be beholden for correctness to things being as they are? In no way.

The present intentionalist version of disjunctivism's target thus ends up in just the same boat as our initial more straightforward version. For the straightforward version it turned out in the end that there was nothing it could be to be confronting non-environmental red, no range of cases which were the ones of things being that way -not even in a new sense of 'red', for, in the non-environmental case there is no such sense to be introduced. In the intentionalist case it turns out in the end that there is nothing it could be to confront (what turns out to be) non-environmental representing of it as so that $\mathrm{P}$, no range of cases which would be ones of confronting that-not even in some new sense of 'represent'. For, in the desired case there is no such sense to be had. The root trouble with sense-datum theory was not that it required nonenvironmental bearers of properties like being yellow, or ovoid, or pebble-grained. It 
was rather the prior idea of ways things non-environmentally are.

Faced with this trouble, an intentionalist might try to make his postulated representing something environmental-perhaps something neurological. But an environmental anchor, of that sort, or of any other, would re-instate the possibility of ringer-states, with ringers for given representing. Which, as we have seen, would sabotage the intentionalist project in a different way. If we were to waive this point, I might then need to unbracket the points I have so far waived, about the intelligibility, anyway, of the idea of representing without an agent. But that would be another project.

Disjunctivism's target walks a narrow line. On the one hand, in all its forms, it posits something in (an) experience distanced enough from the experiencer to be something there to respond to, and, specifically, something to judge about: something one can take to be one way or another, rightly or wrongly according to how it anyway is -thus, something fit to decide that correctness to which judgement is peculiarly liable. On the other, this something is to be so closely tied to the experiencer that it would not be there at all but for the experience it is part of. Frege's point is: this trick cannot be turned. In targeting idealism, Frege targeted-most strikingly, perhaps, but not exclusively-the idea of non-environmental sensory objects of judgement. It is noteworthy that intentionalism falls within his target's scope.

7. Varieties of Attitude: We do have inner lives. There is something it is like to be me, something it is like to experience what I do (on an occasion). I frequently respond to my inner life. Such responses may be part of what is to be met with, as when I say, 'Everything is spinning.' What is thus to be met with may be important-without, for all that, being a judgement as to how things are for me alone. If they are responses to what I alone could be aware of-towards something otherwise inaccessible being as it is -then their standing as they do towards what they do is not something to be met with. They cannot, thus, be judgements. So much for disjunctivism's target. In an experience of perceiving (e.g., seeing) things, we do not encounter what, on the one hand, there could be to be encountered anyway, regardless of the layout of the scene in view (thus, something not to be met with) and something which is, or not, determinate ways it may be judged to be. Perception is an encounter with the environment, in which we are more or less sensitive, more or less accurately, to its being as it is. It is occasion for responding to just that. It supplies sensory awareness of nothing else to judge about.

Using 'inner sense' for a mode of awareness whose objects are nonenvironmental, John McDowell has said, 
If we can make out that judgements of "inner sense" are about anything, it has to be that they are about impressions of "inner sense" themselves, not about something independent of which the impressions constitute awareness.

This is a very difficult area. Wittgenstein himself sometimes seems to betray an understandable wish to duck the difficulties. What I have in mind here is the fact that he sometimes seems to toy with denying that self-ascriptions of sensations are assertions, articulation of judgements about states of affairs at all. (1994, p. 22)

For judgements of 'inner sense' to be about impressions of inner sense is for them to turn, for correctness, on how those impressions are, namely, whether they are thus and so. I have denied that judgement could be like that-that there are such things for it to turn on. McDowell seems to suggest that this is 'ducking difficulties' and a cop-out. But it is not. We have feelings, which sometimes matter deeply to us, to which we respond in ways which matter to what we thus feel. And, perhaps, sometimes vice-versa. It is just that what we respond to does not matter to our responses in the way a judgement as to an impression's being thus and so would.

McDowell is nearly right when, crediting Miles Burnyeat, he says,

In ancient scepticism, the notion of truth is restricted to how things are ... in the world about us, so that how things seem to us is not envisaged as something there might be truth about ... whereas Descartes extends the range of truth and knowability to the appearances on the basis of which we naively think we know about the ordinary world. In effect, Descartes recognizes how things seem to a subject as a case of how things are; and the ancient sceptics' concession that appearances are not open to question is transmuted into the idea of a range of facts infallibly knowable by the subject involved in them. (1986/1998, p. 239)

Descartes, McDowell tells us, misconstrues Pyrrhonian appearances as judgements-a first step on his road to ruin. But appearances may be any of several things. (Conflating these can make one impose the shape of an attitude on what is not one.) The appearances on the basis of which we naively think we know about the world are 
appearances which the world, and its denizens, have. These are not attitudes. For Descartes to go wrong in the cited way would be for him to make an attitude of something that is not. Whereas Pyrrhonian appearances are to be precisely non-truthevaluable attitudes. Something may appear to me to be thus and so not in my detecting its so appearing (which would bring back into the picture just what the Pyrrhonians wanted to eliminate: to detect is, inter alia, to take something to be so), but rather in my holding a certain view. The Pyrrhonian suggestion was that this may be a non-truthevaluable view-not judgement: no matter how things are, for all that, things so appeared to me. Such appearances, they held, may substitute for thinking-so in guiding action. I may, not unreasonably, move out of the cart's path because of how things seem to me. So what the Pyrrhonians meant to point to was precisely a way for an attitude to matter (inter alia to conduct) without being a judgement.

In a way, then, ancient sceptics were one with Frege. There is not always room for judgement, nor need there be. A judgement is beholden to how things are in a way there is not always room for. The ancient's seemings-to-one-to-be are not so beholden. They are attitudes available anyway even where judgement is not. If a seeming to be cannot be false, this does not mean that there is judging which is immune to error. To understand inner life we need to see the various ways in which such attitudes may be important.

For this we can again turn to Frege. Describing a patient in pain Frege says,

The patient who has a pain is the bearer of this pain ... the doctor who treats him, who thinks about the cause of this pain, is not a bearer of the pain.... The patient's pain may correspond to an image in the doctor's consciousness; but this is not the pain, and not that which the doctor is concerned to remove. Perhaps the doctor consults another. Then we need to distinguish: first, the pain, whose bearer is the patient; second, the first doctor's image of it, third the second doctor's image of it. This image belongs, of course, to the contents of the second doctor's consciousness, but is not the object of his thought, though perhaps an aid to that thought, as a symbol might be. Both doctors have as common object [of thought] the patient's pain, whose bearer they are not. One can see from this that not only a thing, but also an idea, can be the common object of thought of people who do not have that idea. (1918, p. 73) 
The patient is the one in pain. Only he has the pain. Only he undergoes his experience. But (Frege's point is) his having the pain may be part of the environment: something to be met with (in space), e.g., by the two doctors; something thus, and thereby, to be judged about. His being in pain is to be met with in space; judgements as to his pain are thus to be met with in thought. The patient's attitudes towards his pain may be to be met with. But they need not be judgements as to the features of that which is not to be met with, and which he encounters in being in pain. There are other ways for these attitudes of his to relate to his being in pain. They need not be judgements at all.

The point generalizes. Wherever someone is, psychologically, a certain way, his so being is a feature of the environment. It is something to be met with, not merely something to be met with by the subject. It is the sort of thing that may be observable, or ascertainable, where these are environmental notions. Frege shows us why this must be right. Someone's attitudes towards how it is for him-towards his undergoing, or feeling, sensing, etc., what he does-may be an important part of what is to be met with in his being, psychologically, thus and so. The sort of role such reactions play in his so being depends very much on the case in hand. But there is a wide range of roles those reactions could not play if they were judgements as to how things were with him. It is important that there are other things for such attitudes to be.

Where someone's being thus and so is part of the environment, his being so may be something he encounters in a way no one else can. Insofar as it is his so beingsomething environmental-which he thus encounters, he encounters something he can judge about. Some of our attitudes towards ourselves may sometimes correctly be so understood. I may encounter myself sitting, or speeding up as I walk across the quad (late again). I thus encounter something there is for me to judge: I have started to walk very fast. I do not mean here to set limits to what can be so understood. I merely point to the importance of understanding some of our attitudes towards ourselves otherwise -an importance I can here no more than gesture at.

There is, notably, the case of pain. Pain is, notoriously, the sort of thing one minds (even if one would welcome it, administered by a lover), the sort of thing which, if severe enough, one would find awful. How one minds one's pain may be integral to its being the sort of pain it is. When the patient says, 'It is becoming unbearable', that may express, or manifest, not canniness, nor acuity in observation, but rather a response in which its being unbearable pain he experiences (in part) consists.

Again, walking home, I say to you, 'I think there is enough beer at home to last the match.' I express an attitude towards my refrigerator, which is, unproblematically, judgement. In saying what I think, I may also, sometimes, for some purposes, be 
viewable as manifesting an attitude towards my being as I am. My response towards my standing towards the world as I do may express acknowledgement of the world's, or experience's, power over me; my lack of choice as to what to think. To take there to be beer at home is precisely to lack such choice. My acknowledgement, or acquiescence in the world's power here may thus just be part of what it is for me to think so.

Or, again, something tasting not at all like chocolate may, just for a moment, taste of (hints of) chocolate to me. It seemed to me to have such hints. Is this seeming an attitude, or a matter of its tasting, momentarily, a certain way? Well, perhaps, inter alia, an attitude (in which case not one of judging). But then, perhaps also, something's tasting thus and so to me. Perhaps, so responding, in the right surroundings, just is part of things so tasting.

Frege set himself consciously and with determination against a view of perception which was pervasive in the $19^{\text {th }}$ century, and much of the last, and which, I have tried to show, is still operative in the view the rejection of which just is disjunctivism. In its full traditional form, it has a very odd feature. It begins with the question what we see (hear, etc.), and ends with, as answer, objects of awareness which could not possibly be objects of sight (or etc.) As Frege puts it,

Ideas cannot be seen, or felt, neither smelled nor tasted, nor heard.

I take a walk with a companion. I see a green meadow; I have thereby a sense-impression of green. I have it, I do not see it. (1918, p. 67)

Frege saw that he needed an environment, and thus perception, and not merely sensation, if there was to be something for logic to be about. Not that logic applies only to environmental thoughts. But rather, only given an environment for thinkers can the notion of judgement gain a foothold. The position disjunctivism opposes need not go so far as to propose as objects of perception what could not be that-what does not belong to an environment. But in positing perceptual experiences outside of an environment it strays beyond the bounds of judgement. The oddity it thus collapses into entirely parallels that strange idea of seeing what could not be in sight. ${ }^{1}$

Charles Travis

King's College London 
(for Philosophical Topics, Fall 2005

\section{References}

"Either/Or: disjunctivism for dummies", Alex Byrne and Heather Logue, forthcoming in Disjunctivism: Perception, Action, Knowledge, eds. Adrian Haddock and Fiona Macpherson, OUP.

Frege 1918: Gottlob Frege, "Der Gedanke", Beiträge zur Philosophie des deutschen Idealismus 2 (1918-1919), pp. 58-77.

Hinton 1973: Michael Hinton, Experiences, Oxford: Oxford University Press, 1973.

McDowell 1994: John McDowell, Mind and World, Cambridge, MA: Harvard University Press, 1994.

McDowell 1998: John McDowell, "Singular Thought and the Extent of Inner Space", Subject, Thought and Context, J. McDowell and P. Pettit, eds., Oxford: Oxford University Press, 1986. Reprinted in Meaning, Knowledge and Reality, Oxford: Oxford University Press, 1998, pp. 228-259.

Waismann 1979: Friedrich Waismann, Wittgenstein: Conversations with the Vienna Circle, Oxford: Basil Blackwell, 1979.

1 Those without whom not are, this time, as not unusually, Mike Martin and Joan Weiner. Thanks also to Alex Byrne, Charles Parsons, Sharon Berry and Eylam Ozultun. 